\title{
Evaluation of Loose Assemblies Using a Multi-frequency Eddy Current Method and Artificial Neural Networks
}

Đánh giá chất lượng các cấu trúc ghép lớp kim loại sử dụng phương pháp dòng điện xoáy đa tần và mạng nơ-ron nhân tạo

\author{
Thanh - Long Cung \\ School of Electrical Engineering, Hanoi University of Science and Technology, Hanoi, Vietnam \\ Email: long.cungthanh@hust.edu.vn
}

\begin{abstract}
The paper deals with the non-destructive evaluation of the airgap existing between parts in loose metallic assemblies, using the eddy current (EC) method. In this study, the relationship between the variations of the impedance of a ferrite-cored coil sensor and an assembly featuring two aluminum plates is analyzed. Then artificial neural networks, based on statistical learning of the relationship between a sensor and an assembly are proposed and developed using both simulated and measured multi-frequency EC data, so as to estimate the distance between the assembly parts in a range from $0 \mu \mathrm{m}$ to 500 $\mu m$. For the neural network built on experiment data, the inaccuracy of obtained results is smaller than $1.06 \%$.
\end{abstract}

Keywords: non-destructive evaluation, eddy currents, normalized impedance distance, multilayer feed-forward neural network

\section{Tóm tắt}

Bài báo trình bày phuoong pháp đánh giá không phá hủy sủ dụng dòng điện xoáy, nhằm xác định độ dày của khe hở không khi tồn tại giữa các lớp ghép kim loại. Trong nghiên cưu này, mối liên hệ giữa sự thay đổi tổng trở của cảm biến dòng điện xoáy với cấu trúc ghép gồm hai phiến hợp kim nhôm được phân tích. Tù đó, các mạng nơ-ron nhân tạo được đề xuất và xây dựng trên co sở các tập dũ liệu mô phỏng và thực nghiệm, thống kê mối quan hệ giữa cảm biến và cấu trúc kiểm tra, nhằm uớc luợng khoảng cách giũa các phiến ghép nằm trong khoảng tùi $0 \mu$ m tới $500 \mu \mathrm{m}$. Với mạng no-ron xây dụng trên tập dũ liệu thí nghiệm, sai số của kết quả ước luợng không vuợt quá 1,06\%.

Từ khóa: đánh giá không phá hủy, dòng điện xoáy, khoảng cách tổng trở chuẩn hóa, mạng nơ-ron truyền thẳng nhiều lớp

\section{Introduction}

The non-destructive evaluation (NDE) of metallic assemblies is a major preoccupation in many industrial areas such as aeronautical, railway, automotive, or nuclear industries. This paper deals with the problem of estimation of the distance between assembled parts, in order to detect and characterize loose assemblies. The eddy current (EC) technique is a good candidate to carry out the investigation of these structures. However, the quantitative evaluation of layered structures starting from EC data requires firstly to elaborate an accurate model of the sensor/structure interactions, and secondly, to solve an ill-posed inverse problem $[1,2]$. In order to bypass the difficulties induced by the resolution of these forward and inverse problems, as well as to deal with the uncertainties that may be occurred in experimental setup (inaccurate knowledge of the features of the assembly, mispositioning of the sensor, etc...), one can choose to implement a "non-model" approach from statistical learning of the interactions between the sensor and the investigated structure. In order to implement such an approach, we choose to build an artificial neural network (ANN), which is known to be a universal approximator [3]. Moreover, ANNs have been proved that they are efficient in the solution of NDE problems [4] starting from experimental data [5]. In this study, a statistical approach based on an ANN is used to evaluate the distance between parts in an aluminum assembly, starting from the EC data provided by the interactions between a ferrite cored coil EC sensor and an aluminum mockup. Furthermore, in order to build a robust and accurate ANN, as well as to deal with assemblies of unknown thicknesses, we use EC datasets obtained at different frequencies, which are chosen in an optimal bandwidth.

The paper is organised as follows: section 2 reports on the experimental set-up and the selection of the used multi-frequency EC data. The implementation of the ANN approach is presented in section 3 and the obtained evaluation results are presented and discussed in section 4. Finally, conclusions and some perspectives to our work are given in section 5 .

ISSN: 2734-9381

https://doi.org/10.51316/jst.151.etsd.2021.31.3.14

Received: October 12, 2020; accepted: January 15, 2021 


\section{Experimental set-up and multi-frequency EC data}

The experimental set-up is constituted of a ferrite cup cored coil, used as a "transmit and receive" EC sensor coupled to a mockup standing for a loose assembly featuring two aluminum plates, separated from an adjustable distance $t$ ranging from 0 to $500 \mu \mathrm{m}$, and featuring various thicknesses $(1.5 \mathrm{~mm}$ for the top plate, 1.5 to $25 \mathrm{~mm}$ for the bottom plate) (Fig. 1). The sensor is associated with a PC controlled impedance analyzer and is implemented with excitation frequencies $f$ ranging from $5 \mathrm{~Hz}$ to $30 \mathrm{kHz}$. The EC data that are used in this study are constituted by the impedance variation $\Delta Z$ defined as:

$$
\Delta Z(f)=Z_{n t}(f)-Z_{n 0}(f)
$$

where $Z_{n t}$ and $Z_{n 0}$ are the normalized impedances of the sensor coupled with the assembly when the distance between parts is $t$ and 0 respectively, and where the normalized impedance of the sensor is defined as [6]:

$$
Z_{n}=\left(Z-R_{0}\right) / X_{0}
$$

$Z$ is the impedance of the sensor, $R_{0}$ and $X_{0}$ are the resistance and the reactance of the uncoupled sensor respectively. In previous works, it has been shown both experimentally and computationally that the modulus of $\Delta Z$ is a function of the distance between parts [7]. More precisely, a multifrequency study enabled us to assess that i) there exists an optimal frequency range maximizing the sensor sensitivity towards the distance between parts, ii) only the modulus of $\Delta Z$ is significantly modified by the distance between parts, iii) the modulus of $\Delta Z$ vary linearly with the latter distance within the optimal frequency range, and iv) the variations of $\Delta Z$ as a function of the thickness of the bottom plate are nonlinear. In this paper, in order to estimate the distance between parts starting from $\Delta Z$ when the thickness of the bottom plate is unknown, we chose to build an ANN in a multifrequency framework.

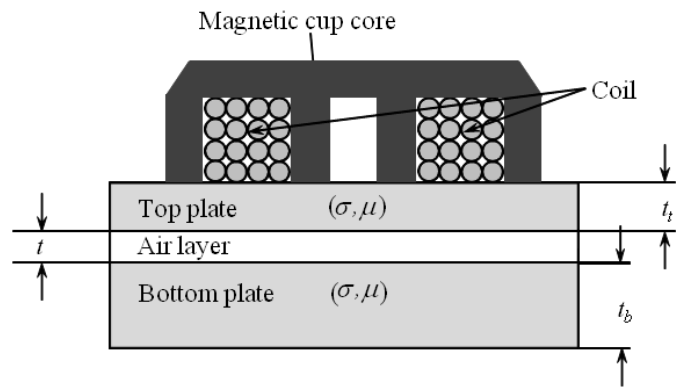

Fig. 1. Experimental set-up [7]

\section{Estimation of the distance between parts using neural networks}

\subsection{General scheme}

The non-model approach implemented in this study consists of constructing a database that can be used to elaborate a behavioral model by statistical learning of the sensor/assembly interactions. The behavioral model is elaborated by adjusting the internal parameters of an ANN, so as to statistically "learn" a relationship between the inputs and the outputs of the ANN. The ANN, after adjusted, can provide outputs which are accurately related to the inputs presented in unknown configurations. In this study, the inputs of the ANN are multifrequency EC data, while the outputs are the distance between the plates of the assembly and the thickness of the bottom plate. More precisely, the EC data used to feed the ANN are constituted of the modulus of the sensor impedance variations $\Delta Z$, as defined in (Eq. 1). The data set is obtained at several frequencies which are chosen in the optimal frequency range [7], in order to optimize the robustness as well as the accuracy of the behavioral model. In this paper, two different cases are considered. First, we build a learning database including EC data provided by multi-frequency finite element computations. The white noise is added to this data set to stand for acquisition noise. This database is used to elaborate $\mathrm{ANN}_{1}$. Then, the $\mathrm{ANN}_{1}$ is characterized using a test set constituted of a new set of noisy simulated data, as well as a set of experimental data featuring the same noise power. $\mathrm{ANN}_{1}$ is elaborated in order to assess i) the relevance of the behavioral learning approach to estimate loose assemblies when a large amount of learning data is available, ii) the robustness and accuracy of an ANN elaborated with simulated data and used with experimental data. Secondly, another ANN, denoted $\mathrm{ANN}_{2}$, is elaborated, based on a learning data set including only multi-frequency experimental data. $\mathrm{ANN}_{2}$ is built to evaluate the relevance of the approach when using a reduced training data set.

\subsection{Elaboration of the data sets}

The simulated EC data set used to generate $\mathrm{ANN}_{1}$ is relative to the following configurations: the distance $t$ between the aluminum plates takes values in the $\{10$, $50,100,150, \ldots, 500 \mu \mathrm{m}\}$ set, and the excitation frequencies take values in the $\{680,1060,1440,1820$, $2200 \mathrm{~Hz}\}$ set. The top plate is $1.5 \mathrm{~mm}$ thick and the bottom plates thicknesses belong to the set $\{1.5,2.0$, $2.5,3.0,3.5 \mathrm{~mm}\}$. As a result, 55 sets of input and output data vectors relative to these configurations are generated by computations. Each output vector is constituted of two elements: the distance $t$ between plates and the thickness of the bottom plate $t_{b}$. Each input vector is constituted of five elements relative to the values of $\Delta Z$ obtained at the 5 considered excitation frequencies. In order to take the uncertainty that may appear in actual EC data into account, white noise has been added to the computed EC data, to generate 55,000 new noisy input data sets. Consequently, 55,000 sets of input/output vectors are available to elaborate and characterize $\mathrm{ANN}_{1}$. 
In addition, an experimental data set is built to elaborate and characterize $\mathrm{ANN}_{2}$. Here, the input vector relative to each assembly configuration is constituted of eight elements $\Delta Z$ measured at 8 different frequencies. Five frequencies are those used for $\mathrm{ANN}_{1}$, and 3 additional frequencies \{2561, 2937, $3313 \mathrm{~Hz}$ \} are used to enlarge the data set. The output vectors feature two elements $t$ and $t_{b}$ as for the output vectors of $\mathrm{ANN}_{1}$. However, here only two plate configurations are considered: the top plate is $1.5 \mathrm{~mm}$ thick and the bottom plate is either $1.5 \mathrm{~mm}$ or $25 \mathrm{~mm}$ thick. The distance between plates is in the set $\{100$, $200,300,400$, and $500 \mu \mathrm{m}\}$. To build the EC databases for $\mathrm{ANN}_{2}, \mathrm{EC}$ data measurements are carried out 12 times in each considered configuration. Then 8 sets of EC measurements are used to build the training data set, while the 4 remaining data are used to test and characterize the $\mathrm{ANN}_{2}$.

\subsection{Configuration of the neural networks}

For both considered ANN, a multi-layered feedforward configuration is used. It is made up of an input layer, a hidden layer, and an output layer (Fig. 2). The "input layer" is only used to transmit the input values to all neurons of the hidden layer. The activation function of the neurons in the hidden layer is the sigmoid function, and that of the neurons of the output layer is a linear function. In both cases, the ANN is trained by the learning algorithm of LevenbergMarquardt [8]. After the training process, the final architecture of $\mathrm{ANN}_{1}$ is set to 5-39-2, (5 inputs, 39 neurons in the hidden layer, 2 outputs) and to 8-4-2, with 4 neurons in the hidden layer for $\mathrm{ANN}_{2}$. These are the architectures that provide the best-estimated results, based on the analysis of the obtained mean square error of the estimation.

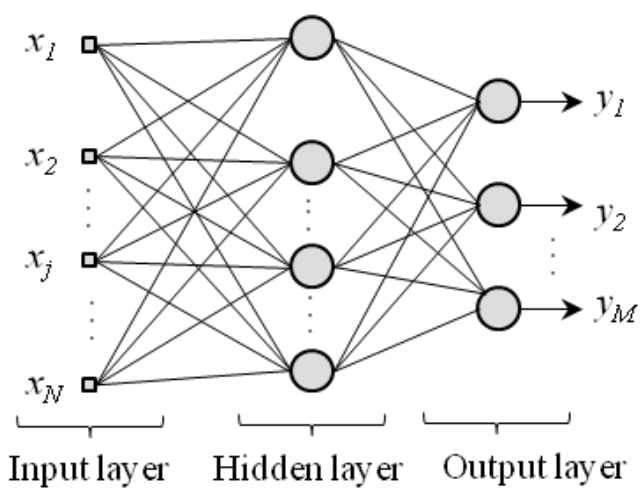

Fig. 2. Multi-layered feed-forward neural network

\section{Results and discussion}

\subsection{Characterization parameters}

To evaluate the reliability and the accuracy of the estimated results, two characterization parameters are defined: the relative precision error $(R P E)$ and the relative accuracy error ( $R A E)$, expressed in (3) and (4), respectively.

$$
R P E \%=\frac{1}{n} \sum_{i=1}^{n}\left(\left(\frac{\sqrt{\frac{1}{m-1} \sum_{y=1}^{m}\left(\hat{t}_{y}-\frac{1}{m} \sum_{y=1}^{m} \hat{t}_{y}\right)^{2}}}{\frac{1}{m} \sum_{y=1}^{m} \hat{t}_{y}} .100\right)_{i}\right.
$$

where $n$ is the number of measurement points of $t$ and $m$ is the number of measures carried out for each assembly configuration.

$$
R A E \%=\frac{1}{n} \sum_{i=1}^{n}\left(\frac{1}{m} \sum_{y=1}^{m}\left(\frac{\hat{t}_{y}-t_{i}}{t_{i}} .100\right)\right)
$$

where $t_{i}$ denotes the actual value of the distance between plates at the $i^{\text {th }}$ measurement point, and $\hat{t}_{y}$ denotes the $y^{\text {th }}$ estimated value of the plate distance corresponding to each $t_{i}$.

In addition, the root mean square error (RMSE) is also used to characterize the elaborated ANN and is defined by:

$$
R M S E=\sqrt{\frac{1}{n} \sum_{i=1}^{n}\left(\frac{1}{m} \sum_{y=1}^{m}\left(\hat{t}_{y}-t_{i}\right)^{2}\right)}
$$

where $\hat{t}_{i}, t$ and $n$ denote the $i^{t h}$ estimation result, the actual value of the distance between plates, and the number of measurement points, respectively.

\subsection{Implementation and characterization of $A N N_{1}$}

First, $\mathrm{ANN}_{1}$ is elaborated with noisy simulated data featuring a $33 \mathrm{~dB}$ signal to noise ratio (SNR) and tested using a new set of noisy simulated data featuring the same SNR. The SNR is adjusted to $33 \mathrm{~dB}$ since it is relative to the noise power measured on the actual experimental data. In order to characterize the evaluation performances of $\mathrm{ANN}_{1}$, the results relative to the thinnest structure $\left(t_{b}=1.5 \mathrm{~mm}\right)$ and to the thickest structure $\left(t_{b}=3.5 \mathrm{~mm}\right)$ are examined, and the results are presented in Table 1 and (Fig. 3a). For the thin structure $\left(t_{t}=t_{b}=1.5 \mathrm{~mm}\right)$, the RAE is $-3.92 \%$, the RPE is $2.71 \%$. For the thickest structure $\left(t_{t}=1.5 \mathrm{~mm}, t_{b}=3.5 \mathrm{~mm}\right)$ the variation of the estimated results is equivalent to that of the previous structure, with a $\mathrm{RPE}=2.74 \%$. However, the average value of the estimated results at each measurement point is obviously better, since the RAE $=0.26 \%$. Thus, the estimated results tend to be better when the bottom plate is thicker. This trend is confirmed by the RMSE which is $23.75 \mu \mathrm{m}$ in the case of the thin structure, and $9.15 \mu \mathrm{m}$ in the case of the thick structure. 
Table 1. Accuracy and precision of the neural network built from simulated data

\begin{tabular}{|c|c|c|c|}
\hline \multicolumn{4}{|c|}{$\begin{array}{l}\text { Configuration of the tested structure: } \\
\qquad t_{t}=t_{b}=1.5 \mathrm{~mm}\end{array}$} \\
\hline Data & $\begin{array}{c}\text { RAE } \\
(\%)\end{array}$ & $\begin{array}{l}\mathrm{RPE} \\
(\%)\end{array}$ & $\begin{array}{c}\text { RMSE } \\
(\mu \mathrm{m})\end{array}$ \\
\hline $\begin{array}{c}\text { Simulated } \\
(\mathrm{SNR}=33 \mathrm{~dB})\end{array}$ & -3.92 & 2.71 & 23.75 \\
\hline $\begin{array}{l}\text { Experimental } \\
(\mathrm{SNR}=33 \mathrm{~dB})\end{array}$ & -4.37 & 2.42 & 27.71 \\
\hline \multicolumn{4}{|c|}{$\begin{array}{l}\text { Configuration of the tested structure: } \\
\qquad t_{t}=1.5 \mathrm{~mm}, t_{b}=3.5 \mathrm{~mm} \\
\end{array}$} \\
\hline Data & $\begin{array}{l}\text { RAE } \\
(\%)\end{array}$ & $\begin{array}{l}\mathrm{RPE} \\
(\%)\end{array}$ & $\begin{array}{l}\text { RMSE } \\
(\mu \mathrm{m})\end{array}$ \\
\hline $\begin{array}{c}\text { Simulated } \\
(\mathrm{SNR}=33 \mathrm{~dB})\end{array}$ & 0.26 & 2.74 & 9.15 \\
\hline
\end{tabular}
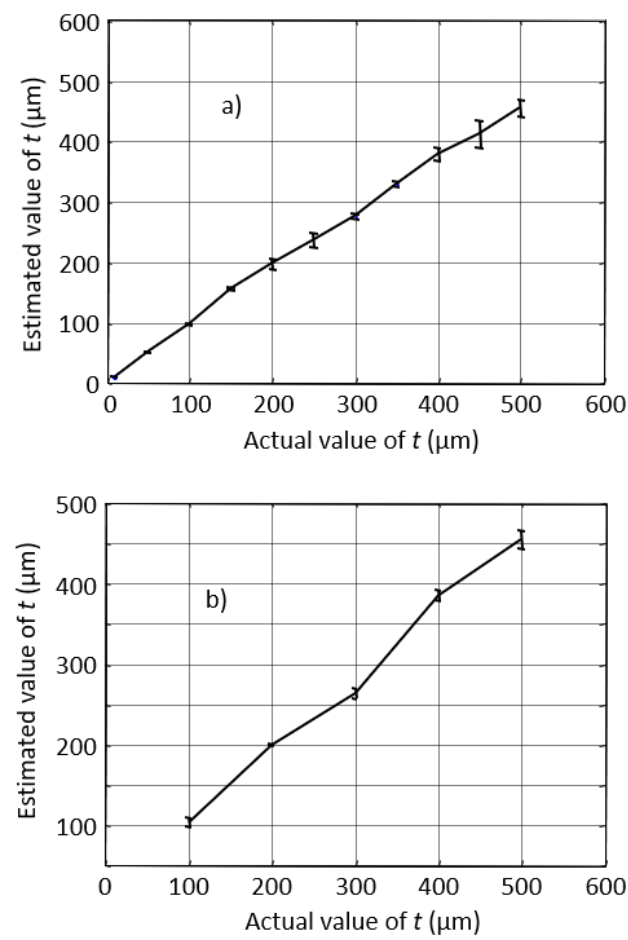

Fig. 3. Estimation results of the neural network built from simulated data: (a) tested with simulated data, (b) tested with experimental data; the $\mathrm{SNR}=33 \mathrm{~dB}$ in both cases.

$\mathrm{ANN}_{1}$ was also tested with experimental data measured on the thinnest structure with $t_{t}=t_{b}=1.5 \mathrm{~mm}$ (Figure 3b). The estimated errors are as follows: $\mathrm{RPE}=2.42 \%, \mathrm{RAE}=-0.37 \%$ and $\mathrm{RMSE}=27.71 \mu \mathrm{m}$. These values show that the estimated results are acceptable although the ANN was built with simulated data.
Table 2. Accuracy and precision of the neural network built from experimental data

Configuration of the tested structure:

\begin{tabular}{cccc}
\multicolumn{4}{c}{$t_{t}=t_{b}=1.5 \mathrm{~mm}$} \\
\hline \hline \multirow{2}{*}{ Estimation of } & RAE & RPE & RMSE \\
& $(\%)$ & $(\%)$ & $(\mu \mathrm{m})$ \\
$t$ & -1.06 & 1.76 & 5.43 \\
$t_{b}$ & -3.21 & 4.18 & 172.92 \\
\hline \hline
\end{tabular}

Configuration of the tested structure: $t_{t}=1.5 \mathrm{~mm}, t_{b}=3.5 \mathrm{~mm}$

\begin{tabular}{cccc}
\hline \hline Estimation of & $\begin{array}{c}\text { RAE } \\
(\%)\end{array}$ & $\begin{array}{c}\text { RPE } \\
(\%)\end{array}$ & $\begin{array}{c}\text { RMSE } \\
(\mu \mathrm{m})\end{array}$ \\
$t$ & -0.61 & 1.32 & 4.34 \\
$t_{b}$ & 0.02 & 0.03 & 13.00 \\
\hline \hline
\end{tabular}
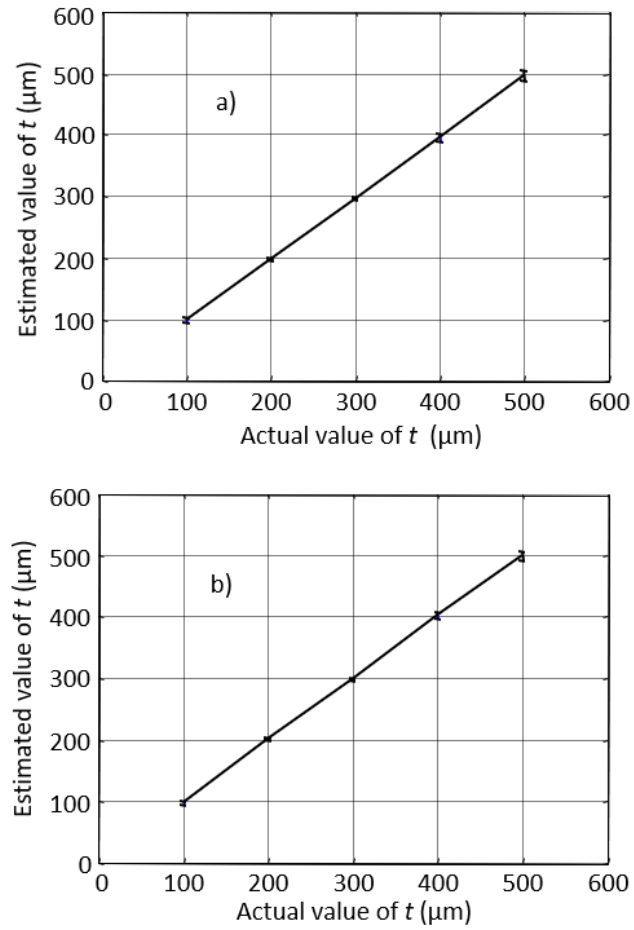

Fig. 4. Estimated results given by $\mathrm{ANN}_{2}$ built from experimental data (tested with a new experimental data set): (a) for the thin structure $\left(t_{t}=t_{b}=1.5 \mathrm{~mm}\right)$, (b) for the thick structure $\left(t_{t}=1.5 \mathrm{~mm}, t_{b}=25 \mathrm{~mm}\right)$.

\subsection{Implementation and characterization of $A \mathrm{NN}_{2}$}

$\mathrm{ANN}_{2}$ is elaborated using a set of experimental EC data, and tested with a new set. The obtained results are satisfactory as shown in Figure 4. We can see that the dispersion of the results is small (Table 2), with $\mathrm{RPE}=1.76 \%$ for the thin structure $\left(t_{t}=t_{b}=1.5 \mathrm{~mm}\right)$, and $\mathrm{RPE}=1.32 \%$ for the thick structure $\left(t_{t}=1.5 \mathrm{~mm}, t_{b}=25 \mathrm{~mm}\right)$. These values 
indicate that the estimations are reliable. The estimated results are accurate too, with the $\mathrm{RAE}=-1.06 \%$, and the $\mathrm{RAE}=-0.61 \%$ for the thin and the thick tested structure, respectively. In this application, one can note that the estimation of the bottom plate thickness is also correctly achieved, as presented in Table 2. Here, again, one can note that the thicker the bottom plate, the better the estimated results.

\section{Conclusion}

In this study, the estimation of the distance between the plates of aluminum assemblies was carried out thanks to statistical behavioral models. The models were elaborated using a multi-frequency EC database used to adjust ANNs. The accuracy of obtained estimation results is good enough to apply to real industrial applications. For our further works, we focus on thicker assemblies, different kinds of materials of tested structures, as well as on the design of an EC sensor for the evaluation of more realistic industrial assemblies. Moreover, the number of used excitation frequencies will also be optimized.

\section{References}

[1]. A. N. AbdAlla, M. A. Faraj, F. Samsuri, D. Rifai, K. Ali, and Y. Al-Douri, Challenges in Improving the Performance of Eddy Current Testing: Review, Measurement and Control, vol 52, no. 1-2, (2019), pp. 46-64.

https://doi.org/10.1177/0020294018801382

[2]. N. Yusa, H. Huang, and K. Miya, Numerical evaluation of the ill-posedness of eddy current problems to size real cracks, NDT\&E International, vol 40, no. 3, (2007), pp. 185-191.

https://doi.org/10.1016/j.ndteint.2006.10.012

[3]. K. Hornik, M. Stinchcombe, and H. White, Multilayer feedforward networks are universal approximators, Neural Networks, vol. 2, no. 5, (1989), pp. 359-366. https://doi.org/10.1016/0893-6080(89)90020-8

[4]. I. T. Renakos, T.P. Theodoulidis, S.M. Panas, and T.D. Tsiboukis, Impedance inversion in eddy current testing of layered planar structures via neural networks, NDT\&E International, vol. 30, no. 2, (1997), pp. 69-74. https://doi.org/10.1016/S0963-8695(96)00047-3

[5]. N. Yusaa, W. Chengb, Z. Chena, and K. Miyaa, Generalized neural network approach to eddy current inversion for real cracks, NDT\&E International, vol. 35, no. 8, (2002), pp.609-614.

https://doi.org/10.1016/S0963-8695(02)00048-8

[6]. S.N. Vernon, The universal impedance diagram of the ferrite pot core eddy current transducer, IEEE Trans. on Magnetics, vol. 25, no. 3 (1999), pp. 2639-2645. https://doi.org/10.1109/20.24503

[7]. T. L. Cung, P.-Y. Joubert, E. Vourc'h, P. Larzabal, On the interactions of an eddy current sensor and a multilayered structure, Electronics Letters, vol 46, no. 23 (2010), pp.1550-1551. https://doi.org/10.1049/el.2010.2611

[8]. M.T. Hagan, M. Menhaj, Training feed forward networks with the Levenberg-Marquardt Algorithm, IEEE Trans. on Neural Networks, vol. 5, no. 6, (1994), pp. 989-993. https://doi.org/10.1109/72.329697 